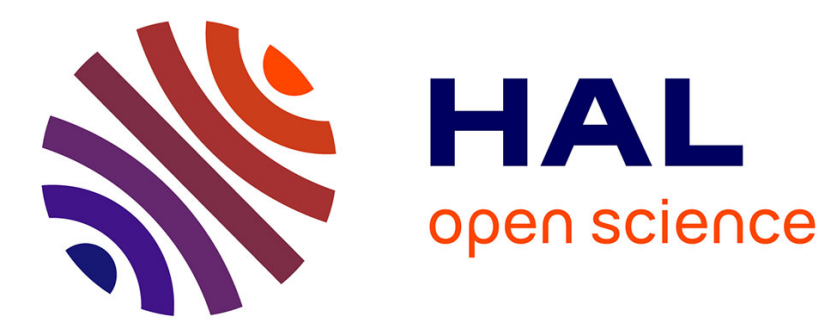

\title{
Customizable Interoperability Assessment Methodology To Support Technical Processes Deployment In Large Companies
}

Clémentine Cornu, Vincent Chapurlat, Jean-Marc Quiot, François Irigoin

\section{- To cite this version:}

Clémentine Cornu, Vincent Chapurlat, Jean-Marc Quiot, François Irigoin. Customizable Interoperability Assessment Methodology To Support Technical Processes Deployment In Large Companies. Annual Reviews in Control, 2012, vol.36 (No. 2), pp 300-308. hal-00790040

HAL Id: hal-00790040

https://hal-mines-paristech.archives-ouvertes.fr/hal-00790040

Submitted on 19 Feb 2013

HAL is a multi-disciplinary open access archive for the deposit and dissemination of scientific research documents, whether they are published or not. The documents may come from teaching and research institutions in France or abroad, or from public or private research centers.
L'archive ouverte pluridisciplinaire HAL, est destinée au dépôt et à la diffusion de documents scientifiques de niveau recherche, publiés ou non, émanant des établissements d'enseignement et de recherche français ou étrangers, des laboratoires publics ou privés. 


\title{
Customizable Interoperability Assessment Methodology To Support Technical Processes Deployment In Large Companies
}

\author{
Clémentine Cornu*, Vincent Chapurlat**, Jean-Marc Quiot*, François Irigoin*** \\ * Eurocopter, ETZR, Aéroport International Marseille Provence 13725 Marignane Cedex - France \\ (e-mail: \{Clementine.Cornu; Jean-Marc.Quiot\}@eurocopter.com) \\ ** LGI2P - Site EERIE de l'EMA, Parc Scientifique George Besse 30035 Nîmes cedex 1 - France \\ (e-mail: Vincent.Chapurlat@mines-ales.fr) \\ *** Mines ParisTech - CRI, 35 rue Saint Honoré, 77305 Fontainebleau Cedex - France \\ (e-mail: François.Irigoin@mines-paristech.fr)
}

\begin{abstract}
Increasing competition on markets induces a vital need for companies to improve their efficiency and reactivity. For this, a solution is to deploy, improve and manage their processes while paying a special attention on the abilities of the resources those involve. Particularly, the interoperability of the latter is considered in this article as a challenge conditioning the success of the deployment. Consequently, this paper presents a methodology to assess interoperability of people, material resources and organisation units involved or that could be involved in a process, all along the deployment effort. This methodology is usable for prevention, detection and correction of interoperability problems.
\end{abstract}

Keywords: Interoperability Assessment, Process, Enterprise Systems Engineering

\section{INTRODUCTION}

The deployment of new processes in a company results from a strategic decision. Indeed it consists in the modification of existing activities or in the addition of new ones considered as required and relevant to the business strategy. The deployment effort can be then broken down into three stages:

- $\quad$ Stage 1: a pre-deployment stage including modelling activities (to capture the as-is situation), preparation of the deployment project and analysis of the effort required to define processes to deploy,

- Stage 2: a per-deployment stage consisting then in practical and effective implementation of the retained process,

- $\quad$ Stage 3: a post-deployment stage including process management and continuous improvement.

Thus, a deployment involves many stakeholders and material resources belonging to the company or to its partners that may experiment collaboration difficulties. Therefore, to succeed in a deployment effort, companies have not only to organize their effort [1] but also, to master the complexity of required interactions between all people, organisations and material resources involved in:

- Stage 1: in the definition of the technical process to deploy but also of the deployment management process,

- $\quad$ Stage 2: in the application of changes planned during predeployment,

- $\quad$ Stage 3: in the daily execution of the technical process deployed and in its management process in charge of monitoring and improving its performances.
The research at the origin of this article aims to propose a methodological guide to succeed in the deployment Systems Engineering processes [2] in a large company. In this work, it is assumed that the risk of deployment failure is maximized by two major factors. The first factor is the lack of skills available in the company required by the technical process to deploy (e.g. the lack in Systems Engineering skills). The second factor is the lack of anticipation, during the predeployment phase, of interactions difficulties that may occur during per and post-deployment stages. Hence, this article focuses on this second factor and addresses the interoperability characteristic of entities (people, organisation units and material resources) that may have a role during the deployment. More precisely, it describes an interoperability assessment methodology which purpose is threefold:

To anticipate interactions difficulties by assessing an interoperability score of entities involved,

- Identify the causes and determine corrective actions,

- Monitor the evolution of this level of interoperability to ensure that correctives actions are efficient.

Thus, this article begins with the presentation of a start of the art about interoperability assessment solutions. Then, entities that need to be assessed and the proposed methodology are presented and illustrated. Next, the assessment process and methods are presented first globally and then in details with their mathematical descriptions. Finally, before concluding a set of questionnaires enabling to apply the assessment methodology is introduced along with the way to interpret them. 


\section{INTEROPERABILITY ASSESSMENT: STATE OF THE ART AND DISCUSSION}

\subsection{Characterization of interoperability for assessment}

Among various available definitions of interoperability, we retain the definition of [3] : "ability of enterprises and entities within those enterprises to communicate and interact effectively". It underlines the crucial necessity for companies to become able to manage their interoperability i.e. to detect problems, analyse situations, improve, and generalize improvement actions. Indeed, it is a key factor for successful partnerships between companies and high satisfaction for customers. Unfortunately to keep a high level of interoperability is not trivial. The first cause is the huge number of obstacles to interoperability and the variety of their concerns. For this, their classification in "interoperability barriers" (technological, conceptual and organisational ) of [4] is very structuring. The second cause is the difficulty to assess interoperability characteristic of the company since it implies to have available solutions to appraise it.

To that end, it is suggested to adopt the two complementary characterisations of interoperability proposed by [5]. The author distinguishes extrinsic/intrinsic and potential/effective interoperability. On one hand, "extrinsic interoperability" refers to the characteristic of a couple of entities to efficiently collaborate together, whereas "intrinsic interoperability" only focuses on abilities of a single resource. On the other hand, the distinction between potential and effective interoperability is established considering the moment of the assessment. If the assessment is done before any collaboration we talk about "potential interoperability" but if the assessment is done once the collaboration has started or is complete, we talk about "effective interoperability".

\subsection{Assessment means: needs}

Crossing the definition and characterizations seen above, the interoperability assessment needs that shall be met during a process deployment are summarized in the Interoperability Assessment Matrix shown Table 1 to enable deployment team becoming able:

- During pre-deployment stage, to identify the current difficulties and to appraise the validity of new partnerships considered by the deployment team to improve current processes,

- During per and post deployment stages, to appraise the progress achieved, to compare it with expected results, and then to define new corrective actions or adjust deployment objectives consequently.

The goal is then to provide a method that first enables, before or after beginnings of their partnerships, estimating:

- The native ability of single entities to be interoperable with any other type of entity,

- The ability of couples of entities to be interoperable when involved in a partnership together.

Second, the assessment tool shall point out where interoperability difficulties are and what are the interoperability barriers concerned in order to take corrective actions.

Third, considering the few time generally accorded to improvement actions in companies, assessment mean also have to:

- Be easily understandable by their users, to limit training effort, and by their managers so that they do not block the use of the assessment tool under the pretext that it is not adapted to companies need,

- Be easily and quickly applicable (this includes the fact that it shall provide enough pragmatic details).

Finally, for this work, additional constraints have been imposed by the company that requested this research. It does not want to have different tools with similar functions. So the assessment tool shall cover all cells of the assessment matrix. Besides it wants an open-ended tool that supports enrichment/customisation.

\begin{tabular}{|c|c|c|c|}
\hline & \multicolumn{2}{|c|}{ OBJECT OF THE ASSESSMENT } \\
\hline & & $\begin{array}{l}\quad \text { INTRINSIC } \\
\quad \text { interoperability } \\
\text { The ability of a single } \\
\text { system to be } \\
\text { interoperable }\end{array}$ & \begin{tabular}{l}
\multicolumn{1}{c}{ EXTRINSIC } \\
\multicolumn{1}{c}{ interoperability } \\
The ability of a couple \\
of systems to be \\
interoperable
\end{tabular} \\
\hline 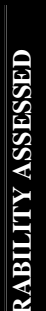 & $\begin{array}{l}\text { POTENTIAL } \\
\text { interoperability } \\
\text { The potential } \\
\text { ability of one or } \\
\text { two systems to } \\
\text { be interoperable } \\
\text { during a } \\
\text { collaboration }\end{array}$ & $\begin{array}{l}\text { The purpose here is } \\
\text { to evaluate the ability } \\
\text { of the entity to } \\
\text { interoperate with any } \\
\text { partner. The partner } \\
\text { is not known. }\end{array}$ & $\begin{array}{l}\text { The purpose here is to } \\
\text { evaluate the future } \\
\text { interoperability of the } \\
\text { couple during } \\
\text { collaboration. } \\
\text { The partners know } \\
\text { each other have not } \\
\text { started collaboration } \\
\text { yet. }\end{array}$ \\
\hline 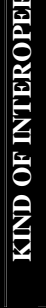 & $\begin{array}{l}\text { EFFECTIVE } \\
\text { interoperability } \\
\text { The real ability } \\
\text { of one or two } \\
\text { systems observed } \\
\text { during a } \\
\text { collaboration }\end{array}$ & $\begin{array}{l}\text { The purpose here is } \\
\text { to evaluate the } \\
\text { effective ability of the } \\
\text { entity to interoperate } \\
\text { with a partner. The } \\
\text { partner is known but } \\
\text { only the } \\
\text { interoperability of } \\
\text { one entity is assessed. }\end{array}$ & $\begin{array}{l}\text { The purpose here is to } \\
\text { evaluate the effective } \\
\text { interoperability of the } \\
\text { couple during their } \\
\text { collaboration. The } \\
\text { partners know each } \\
\text { other and interact. }\end{array}$ \\
\hline
\end{tabular}

Table 1. Interoperability assessment matrix.

\subsection{Assessment means: discussion and synthesis}

Various research works have been developed to support interoperability assessment. We can group them into two categories. The first category is maturity models. The principle is to provide a matrix including a set of levels and factors. The description that best depicts the situation of the company describes the level in which it is. A lot of maturity models for interoperability assessment are available [5-17]. The second category of contributions included quantitative and qualitative assessment means [18-23]. These contributions are confronted to needs previously expressed on Tables 2, 3 and 4. Indeed, first, the row "applicability" provides an indication of the possibility to directly apply the assessment tool in industry by considering the level of details (explanations, examples, etc.). Here, "-" means that it is hard to apply it industry without more information, and "-" the 
opposite. Then the four following rows look at the interoperability assessment types the contributions cover. A "++" indicates that they have been designed for this assessment, a "+" that they have not designed for this purpose but can be nonetheless used, a "-" indicates that they cannot be used for this assessment. Finally the last set of rows indicates the interoperability barriers that are addressed. A "-"means that they do not consider this barrier, a "+" and "++" that they address the barrier respectively lightly or deeply.

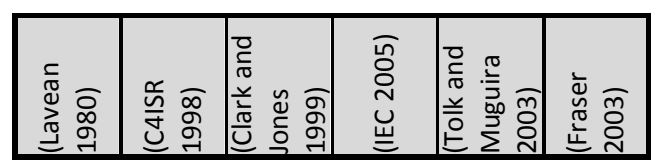

\begin{tabular}{|c|c|c|c|c|c|c|}
\hline Year & 1980 & 1998 & 1999 & 2002 & 2003 & 2003 \\
\hline Applicability & - & + & + & - & + & - \\
\hline
\end{tabular}

\begin{tabular}{|c|c|c|c|c|c|c|}
\hline Extrinsic Pot. & + & + & - & + & - & - \\
\hline Extrinsic Eff. & ++ & ++ & ++ & ++ & ++ & - \\
\hline Intrinsic Pot. & - & - & - & - & - & + \\
\hline Intrinsic Eff. & - & - & - & - & - & ++ \\
\hline
\end{tabular}

\begin{tabular}{|c|c|c|c|c|c|c|}
\hline Concept. & - & + & - & - & ++ & - \\
\hline Orga. & + & - & ++ & - & - & ++ \\
\hline Techn. & + & ++ & - & ++ & + & - \\
\hline
\end{tabular}

Table 3: Comparison of Maturity Models (1/2)

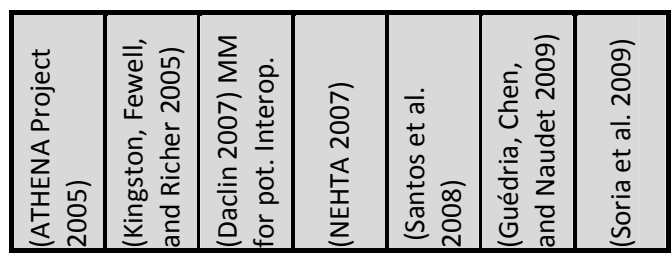

\begin{tabular}{|c|c|c|c|c|c|c|c|}
\hline Year & 2005 & 2005 & 2007 & 2007 & 2008 & 2009 & 2009 \\
\hline Applicability & + & + & - & - & - & - & - \\
\hline
\end{tabular}

\begin{tabular}{|c|c|c|c|c|c|c|c|}
\hline Extrinsic Pot. & - & - & ++ & - & - & ++ & - \\
\hline Extrinsic Eff. & - & - & + & - & - & + & - \\
\hline $\begin{array}{c}\text { Intrinsic } \\
\text { Pot. }\end{array}$ & ++ & ++ & - & ++ & ++ & - & + \\
\hline Intrinsic Eff. & ++ & + & - & + & + & - & - \\
\hline
\end{tabular}

\begin{tabular}{|c|c|c|c|c|c|c|c|}
\hline Concept. & + & + & ++ & ++ & - & ++ & - \\
\hline Orga. & ++ & ++ & ++ & ++ & + & ++ & ++ \\
\hline Techn. & + & - & ++ & ++ & + & ++ & + \\
\hline
\end{tabular}

Table 4: Comparison of Maturity Models (2/2)

Examining these synoptics, it appears first that applicability is unequal. Though this problem could be solved by contacting authors, it is annoying. Then it appears that interoperability barriers are all addressed in very few contributions ([5], [16], [22]). This is limiting since it prevents from addressing all kinds of interoperability problems. Last but not least, none of these contributions covers the four kinds of interoperability assessment in one contribution. Particularly, number of intrinsic interoperability assessment tools is limited ([11-15], [17], [19]) compared to extrinsic ones.

As a consequence, these contributions do not meet the interoperability assessment needs and a new tool has to be proposed. The next section describes an outline of the pragmatic assessment methodology developed in this work.

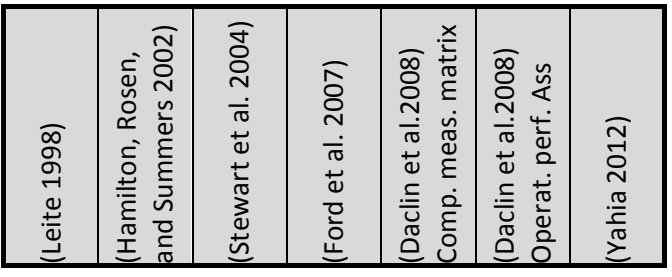

\begin{tabular}{|c|c|c|c|c|c|c|c|}
\hline Year & 1998 & 2002 & 2004 & 2007 & 2008 & 2008 & 2012 \\
\hline Applicability & + & - & - & + & - & + & + \\
\hline Extrinsic Pot. & - & - & ++ & ++ & ++ & - & ++ \\
\hline Extrinsic Eff. & ++ & - & ++ & ++ & + & ++ & ++ \\
\hline Intrinsic Pot. & - & - & - & - & - & - & - \\
\hline Intrinsic Eff. & - & ++ & - & - & - & - & - \\
\hline Concept. & ++ & - & + & - & ++ & - & ++ \\
\hline Orga. & - & - & + & - & ++ & - & - \\
\hline Techn. & ++ & - & - & + & ++ & - & - \\
\hline
\end{tabular}

Table 4: Comparison of other means of assessments

\section{OVERVIEW OF THE PROPOSED ASSESSMENT METHODOLOGY}

This section aims to provide an outline of the pragmatic solution we propose. It first details the different kinds of entities that must be appraised during the deployment effort and then the proposed methodology to perform this appraisal.

\subsection{Entities assessable by the methodology}

During the deployment effort, we need to assess the interoperability of any entity (resource, organisation unit) that collaborates or that could collaborate in the context of the deployment process or of the technical process to deploy. To establish a typology of entities we applied the principle of systematism [24] and identified three kinds of entities:

Human Resources. They are constituted by single persons,

Non-Human Resources. They are constituted by anything that is not a human being (e.g. computer, machine, etc.),

Organisation Unit. They are a structured set of human and non-human resources (e.g. company, department).

Figure 1 identifies the interactions they may have. However interactions between Organisation Unit and Human Resource/Non-Human Resource are not considered here. 
Indeed, they are not relevant since they can be broken down into other interactions that are addressed. We developed the assessment methodology presented in next section according to these categories of interactions.

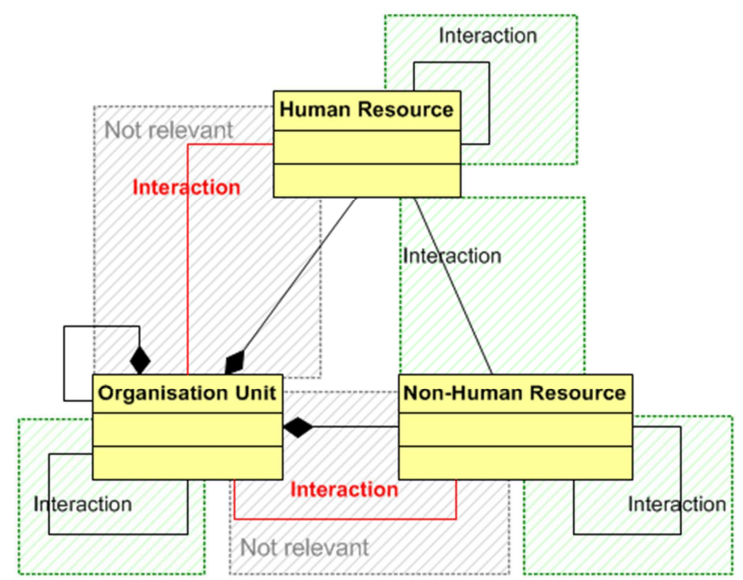

Fig. 1. Types of collaborating systems and interactions

\subsection{The methodology}

As defined by [25], the framework we propose to assess interoperability of entities involved in or impacted by a deployment effort is a "methodology" (see Figure 2). Indeed, it first includes an assessment process describing activities to be conducted. Then, it includes a set of methods that is to say a "set of structured procedures that are based on a conceptual model" [26]. Indeed, on the basis of a metamodel that describes concepts used in all the methodology, we provide procedures explaining how to mathematically assess the entity concerned according to its type and to the type of interoperability assessed. Finally, we propose some tools to support the assessment effort. These are: questionnaires to collect elements on entities to be assessed and a computer application to automate computing of results.

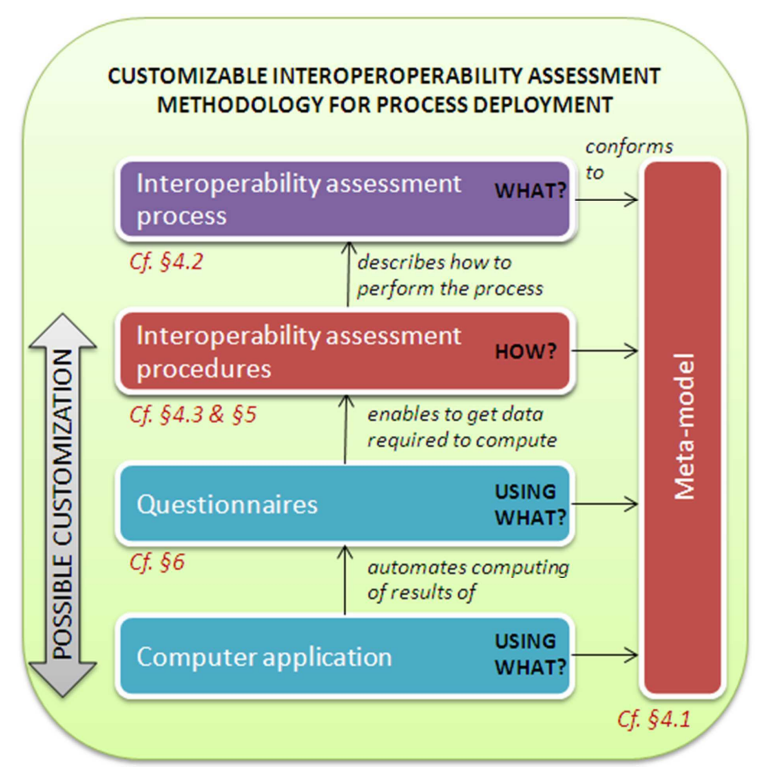

Fig. 2. The Interoperability Assessment Methodology
Next section describes its methodological "heart" i.e. its process and methods.

\section{INTEROPERABILITY ASSESSMENT PROCESS AND METHODS}

This section presents first the semantic basis of the methodology: the meta-model. Then it describes the assessment process we propose along with the procedures to support the latter.

\subsection{The Meta-model}

During the deployment of a process, lots of people may have to manage interoperability assessment activities for each resource involved or that could be involved in the concerned process. Therefore, everything must be done to improve their mutual understanding to reduce the risk of conflicts. To that end, a meta-model is proposed (See Figure 3). Its purpose is to define all concepts and relations between these concepts that are used during the assessment but also during results analyses. For each concept and each relation, a definition in natural language (in both English and French) is provided to guide the assessor. The meta-model presented in is a simplified extract of a bigger meta-model including all concepts required by the deployment effort.

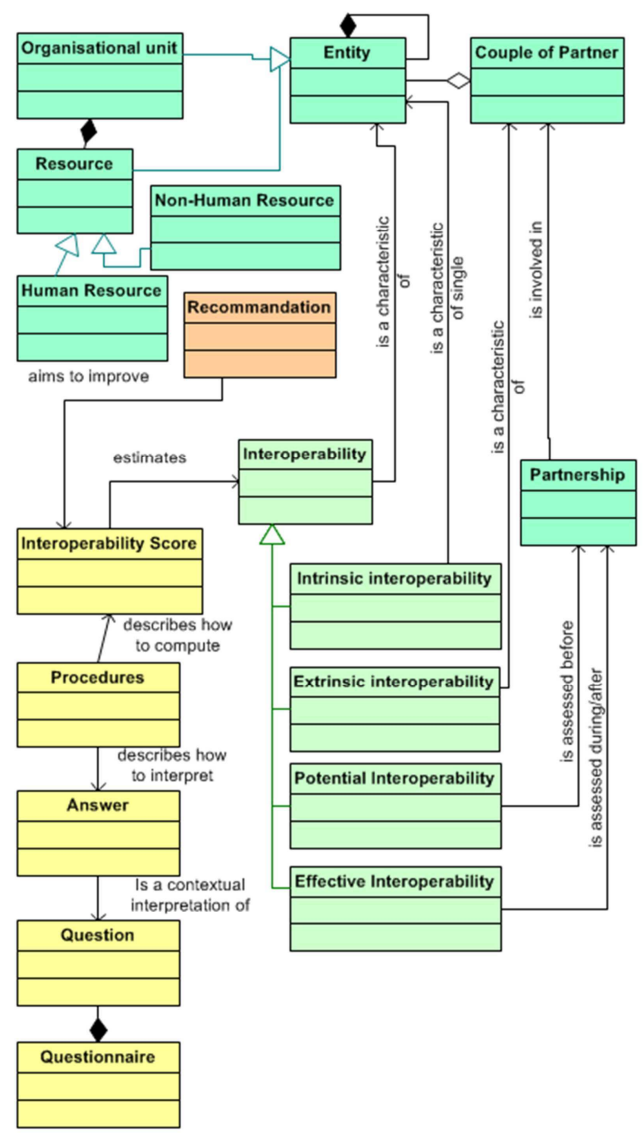

Fig. 3. Simplified extract of the meta-model of the interoperability assessment methodology 


\subsection{The Assessment Process}

The meta-model presented in the previous subsection has constrained the definition of the assessment process presented in Figure 4. The modelling language used to describe it is BPMN 2.0 (standard international process modelling language) [27].

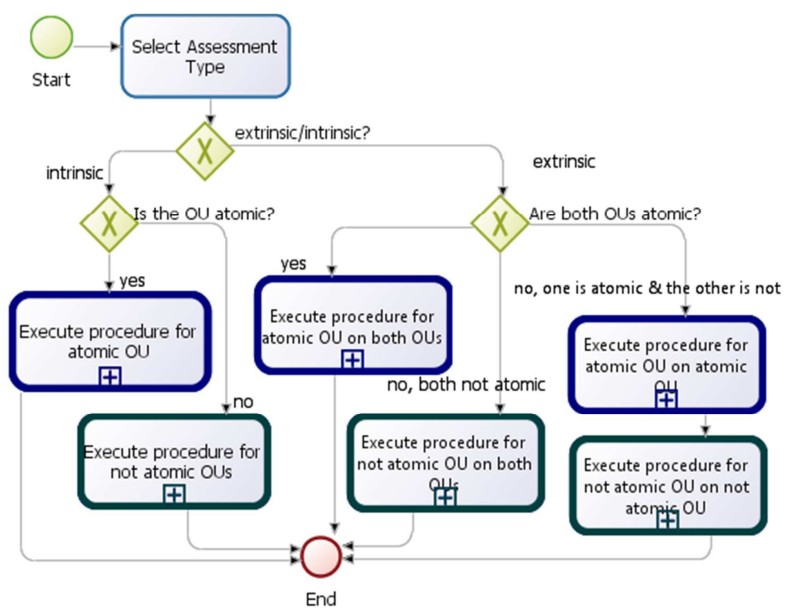

Fig. 4: Global Interoperability Assessment Process

The first activity of the assessment process is to perform the selection of the evaluation we want to perform (cf. Table 1). This conditions the number of organisation units (OU) that are concerned by the assessment activity. Then, according to their nature, different appraisal procedures are executed. Indeed, we distinguish the scenario of an OU that includes only one resource (in this case, we call it "atomic OU") from the one that includes more than one resource (we call it then "not-atomic OU"). In this last case, the nature of both OUs conditions again the type of procedure required. The proposed assessment process cannot be applied directly without methodological practical means for appraisal. Next section presents those that are proposed.

\subsection{The Assessment Procedures}

Two main procedures are available according to the type of Organisation Unit (OU) that is involved. As illustrated on Figure 5 and 6, in the case of atomic OUs, the assessment can be directly done on the basis of questionnaires results.

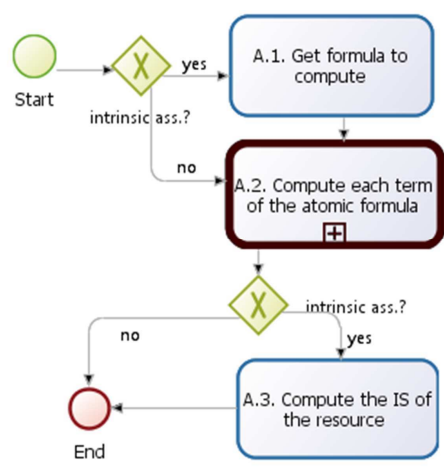

Fig. 5: Sub-process "Execute procedure for an atomic OU"

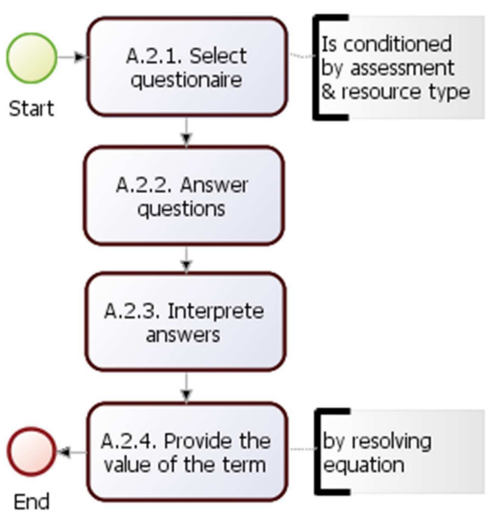

Fig. 6: Details of sub-process A.2.

But, if the OU is not atomic, the calculation of the Interoperability Score (IS) cannot be done until interoperability score of all OU it includes have been computed as described in Figure 7.

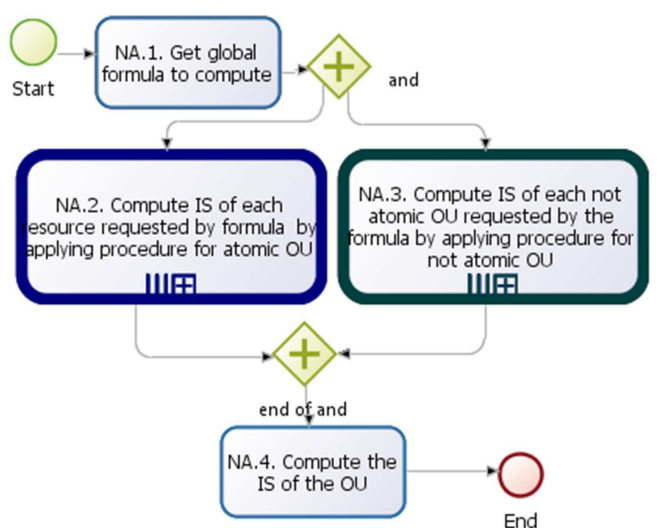

Fig. 7: Sub-process "Execute procedure for not atomic OU"

These assessment procedures require the mathematical formulas described in next Section.

\section{MATHEMATICAL FORMALISATION OF ASSESSMENT METHODS}

After presenting the notations conventions and definitions we adopt, this Section provides all formulas required to perform assessment of atomic and not-atomic OU.

\subsection{Notations}

First, let us call respectively $R H(R N H)$ the set of human resources (non-human resources) internal or external to the company, involved or that could be involved in a process to deploy or in its deployment process. Moreover we call $R$ the whole set of resources:

$$
R=R H \cup R N H \text { with } R H \cap R N H=\varnothing
$$

These resources are allocated to one or several organisation units. We call $U O$ the set of organisation units, internal or external to the company, involved or that could be involved in a process to deploy or in its deployment process. These organisation units can be broken down into resources or other 
organisation units. We call $\operatorname{Dec}_{n}\left(U O_{k}\right)$ the function providing the breaking down of the organisation unit at a level $n$.

Each organisation unit is involved in one or several collaborations as required by the process to deploy or the deployment process. Considering the different types of interoperability presented below, we identify different types of couples of partners. We group them by types and call:

- $\quad C I^{p o t}\left(U O_{k}\right)$ : the set of couples that may be potentially created within $U O_{k}$ between partners identified after the breaking down of the OU,

- $\quad C I_{n}^{\text {eff }}\left(U O_{k}\right)$ : the set of couples of partners both belonging to $U O_{k}$ and effectively involved in a partnership,

- $C E^{\text {pot }}\left(U O_{a}, U O_{b}\right)$ : the set of couples that may be potentially created between two partners belonging respectively to $U O_{a}$ and $U O_{b}$,

- $C E^{e f f}\left(U O_{a}, U O_{b}\right)$ : the set of couples of partners belonging respectively to $U O_{a}$ and $U O_{b}$ and effectively involved in a partnership.

Finally, considering interoperability types, we first call $I_{\text {int }}\left(U O_{a}\right)$ the Intrinsic Interoperability Score of $U O_{a}$ that is defined as:

$$
I_{\text {int }}\left(U O_{a}\right)=\left(I_{\text {int }}^{\text {pot }}\left(U O_{a}\right) ; I_{\text {int }}^{\text {eff }}\left(U O_{a}\right)\right)
$$

With:

- $\quad I_{\text {int }}^{\text {pot }}\left(U O_{a}\right)$ : Potential Intrinsic Interoperability Score of $U O_{a}$

- $\quad I_{\text {int }}^{\text {eff }}\left(U O_{a}\right)$ : Effective Intrinsic Interoperability Score of $U O_{a}$

Besides, we call $I_{\text {ext }}\left(U O_{a}, U O_{b}\right)$ the Extrinsic Interoperability Score of $U O_{a}$ and $U O_{b}$. We define it as:

$$
I_{\text {ext }}\left(U O_{a}, U O_{b}\right)=\left(I_{\text {ext }}^{\text {pot }}\left(U O_{a}, U O_{b}\right) ; I_{\text {ext }}^{\text {eff }}\left(U O_{a}, U O_{b}\right)\right)
$$

With:

- $\quad I_{\text {ext }}^{\text {pot }}\left(U O_{a}, U O_{b}\right)$ : Potential Extrinsic Interoperability Score of $U O_{a}$ et $U O_{b}$

- $I_{\text {ext }}^{\text {eff }}\left(U O_{a}, U O_{b}\right):$ Effective Extrinsic Interoperability Score of $U O_{a}$ et $U O_{b}$

Now that conventions are shared, let us go deeper in the details of formalization.

\subsection{Assessment of atomic organisation unit}

Let us start first with Potential Intrinsic Interoperability Score. It provides an indication on the ability of the resource assessed to well collaborate with other human and nonhuman resources that are not known. Therefore the Potential Intrinsic Interoperability score is defined as:

$$
I_{\text {int }}^{\text {pot }}(r)=\alpha I_{\text {int }}^{\text {pot }}(r)_{r h}+\beta I_{\text {int }}^{\text {pot }}(r)_{n r h}
$$

With :

- $\quad I_{i n t}^{\text {pot }}(r)_{r h}$ : Potential Intrinsic Interoperability Score of the resource $r$ with other human resources. It can be computed using a questionnaire.

- $\quad I_{i n t}^{\text {pot }}(r)_{n r h}$ : Potential Intrinsic Interoperability Score of the resource $r$ with non-human resources. It can be computed using a questionnaire.

- $\alpha, \beta \in[0 ; 1]^{2}$ : pondering coefficient enabling the company to give priority to one type of resources over the other. They are defined considering that $\alpha+\beta=1$. By default, these coefficients equal 0.5 .

Then, let us now address the case of the Effective Intrinsic Interoperability Score. Here, the formula is a little bit different since it has to consider collaborations that are already started or finished. Thus, we define respectively narh (narnh) the numbers of assessments performed about collaboration between the resource and other human resources (non-human resources). Hence, the Effective Intrinsic Interoperability score is given by:

$$
\begin{aligned}
& I_{\text {int }}^{\text {eff }}(r)= \frac{\gamma}{\text { narh }} \sum_{i=1}^{\text {nerh }} \gamma_{i} I_{\text {int }}^{\text {eff }}\left(r, r^{\prime}{ }_{i}\right)_{r h}+ \\
& \frac{\delta}{n a r n h} \sum_{j=1}^{\text {nernh }} \delta_{j} I_{\text {int }}^{\text {eff }}\left(r, r^{\prime \prime}{ }_{j}\right)_{n r h}
\end{aligned}
$$

With:

- $\quad I_{\text {int }}^{\text {eff }}\left(r, r_{i}^{\prime}\right)_{r h}$ : Effective intrinsic interoperability score of the resource with the resource $r^{\prime}$ with ' $\in R H$. It can be evaluated interpreting a questionnaire results.

- $\quad I_{\text {int }}^{\text {eff }}\left(r, r^{\prime \prime}\right)_{n r h}$ : Effective intrinsic interoperability score of the resource with the resource $r^{\prime \prime}$ with $r^{\prime \prime} \in R N H$. It can be evaluated interpreting a questionnaire results.

- $\quad \gamma, \delta \in[0 ; 1]^{2}:$ Like for potential assessment, we introduce two pondering coefficients to give priority of one type of resource over another. They are defined considering that $\gamma+\delta=1$.

- $\gamma_{i}, \delta_{j} \in[0 ; 1]^{2}:$ Pondering coefficients $\gamma_{i}$ and $\delta_{j}$ enabling company to give priority to some previous assessments over others. It may be useful in case of previous appraisals that may be not relevant since they have been done a long time ago. They are defined considering that their sum must equal 1.

Finally, in the case of extrinsic interoperability, no specific formula is used: the interoperability score is directly given by the questionnaire interpretation (see Section 6).

Let us illustrate the use of theses formulas. We take the example of deployment of a technical process as proposed and standardized in Systems Engineering field. The deployment concerns a large company for which deployment strategy and objectives are known, resources and organisation units have been preliminary identified. In this context, we first need to identify where lacks of interoperability are. So focus is put on resources currently involved in the process. The assessment starts with two Systems Engineer (we call them $r$ and $r^{\prime}$ ). They compete to be in charge of a new activity added in the frame of the new process currently under deployment. The deployment team wants to have a 
rough comparison of both to see if one is clearly more interoperable and then would be more relevant for the activity considered. They ask them the questions of questionnaires for potential assessment and get the following results: $I_{\text {int }}^{\text {pot }}(\mathrm{r})_{r h}=30 \% \quad, I_{\text {int }}^{\text {pot }}(\mathrm{r})_{n r h}=90 \%, I_{\text {int }}^{\text {pot }}\left(\mathrm{r}^{\prime}\right)_{r h}=50 \%$ and $I_{\text {int }}^{\text {pot }}\left(\mathrm{r}^{\prime}\right)_{n r h}=70 \%$. In the context of this deployment, the company wants to give priority to interoperability between people and sets $\alpha=0,8, \beta=0,2$. On the basis of equation 1 , they deduce that: $I_{\text {int }}^{\text {pot }}\left(r_{1}\right)=0.8 * 0.3+0.2 *$ $0.9=33,96 \%$ and $I_{\text {int }}^{\text {pot }}\left(r_{2}\right)=0.8 * 0.5+0.2 * 0.7=42 \%$

Thus, it appears that the new Systems Engineer is by nature more interoperable. However, this does not guarantee the success of interactions in which he may take part. Abilities of couples he may constitute with other resources have to be considered and appraised.

After potential extrinsic assessment the second Systems Engineer is finally selected but the deployment team feels the need to evaluate his Effective Interoperability Score to know his real performances during collaboration and to detect his difficulties. Therefore, the deployment team asks him a set of questions about current/previous interactions he has/had in the context of the process. For each resource with who/which it interacts/has interacted, an interoperability score is given after the interpretation of answers (cf. Section 6): $\quad I_{\text {int }}^{\text {eff }}\left(r^{\prime}, \mathrm{r}_{1}\right)_{r h}=40 \%, \quad I_{\text {int }}^{\text {eff }}\left(r^{\prime}, \mathrm{r}_{2}\right)_{r h}=65 \%$, $I_{\text {int }}^{\text {eff }}\left(r^{\prime}, \mathrm{r}_{3}\right)_{n r h}=60 \%$. The company sets: $\gamma=0,8$; $\delta=0,2 ; \gamma_{1}=\gamma_{2}=0,5$ and $\delta_{1}=1$. On the basis of equation 2 , they deduce:

$I_{\text {int }}^{\text {eff }}(r)=\frac{0,8}{2}(0,4+0.65)+\frac{0,2}{1}(0,6)=54 \%$. Therefore, this appraisal enables us to say that this Systems Engineer has currently interoperability issues since his score is far from $100 \%$. To improve his performance, the deployment team can look answers to questionnaires to identify the questions where results were not good and take corrective actions.

\subsection{Assessment of not atomic $O U$}

Let us now introduce formulas required to assess organisation units that are constitutes of other organisation units and or by several resources.

First, let us start with potential intrinsic interoperability score. Its purpose is to provide an indication on the ability of the OU to interoperate with any partner that is not known yet. In an informal way, we can say for an organisation unit $O U_{a}$ it equals to the sum of potential intrinsic interoperability score of each component of $O U_{a}$ and effective intrinsic interoperability score of each component of $O U_{a}$. Let us now consider the effective intrinsic interoperability score. Its purpose is to provide an indication of the ability of an entity to interoperate with a partner that is known. Thus, for an organisation unit $U_{a}$ it can be defines informally as the sum of effective intrinsic interoperability score of each component of $U_{a}$ and effective intrinsic interoperability score of each component of $\mathrm{O} U_{a}$. Therefore, in both case, the following generic formula can be used:

$$
I_{\text {int }}^{x}\left(U O_{a}\right)=\sum_{i=1}^{n a} I_{\text {int }}^{x}\left(p_{i}\right)+\sum_{k=1}^{m a_{\text {int }}^{\text {eff }}} I_{\text {int }}^{\text {eff }}\left(c_{k}\right)
$$

With

$-\quad x=$

$\int^{\prime}$ eff $f^{\prime}$ if we assessed effective interoperability

' 'pot' if we assessed potential interoperability

- $\quad n a=\operatorname{card}\left(\operatorname{Dec}\left(\mathrm{OU}_{\mathrm{a}}\right)\right):$ number of elements of $U O_{a}$,

- $p_{i} \in \operatorname{Dec}\left(\mathrm{OU}_{\mathrm{a}}\right):$ an element of $\mathrm{UO}_{\mathrm{a}}$,

- $\quad c_{k} \in \mathrm{CI}_{\text {na }}^{\text {eff }}\left(\mathrm{OU}_{\mathrm{a}}\right):$ a couple of elements of $\mathrm{UO}_{\mathrm{a}}$ effectively involved in a collaboration,

- $\quad \mathrm{ma}_{\text {int }}^{\text {eff }}=\operatorname{Card}\left(\mathrm{CI}_{\text {na }}^{\text {eff }}\left(\mathrm{UO}_{\mathrm{a}}\right)\right):$ number of couples of entities belonging to $\mathrm{UO}_{\mathrm{a}}$ that are really involved in partnership.

We exemplify the application of this formula by considering two departments impacted by the deployment: $U O_{1}$ and $U_{2}$. They respectively include the following resources and organisation units: $r_{1}, r_{2}$ and $r_{3}, u_{4}, r_{5}$. The application of the equation (3) gives:

$I_{\text {int }}^{x}\left(O U_{1}\right)=\left[I_{\text {int }}^{x}\left(\mathrm{r}_{1}\right)+I_{\text {int }}^{x}\left(\mathrm{r}_{2}\right)\right]+\left[I_{\text {int }}^{\text {eff }}\left(\mathrm{r}_{1}, \mathrm{r}_{3}\right)+I_{\text {int }}^{\text {eff }}\left(\mathrm{r}_{1}, \mathrm{r}_{5}\right)\right.$ $\left.+I_{\text {int }}^{\text {eff }}\left(\mathrm{r}_{1}, \mathrm{u}_{4}\right)+I_{\text {int }}^{\text {eff }}\left(\mathrm{r}_{2}, \mathrm{r}_{3}\right)+I_{\text {int }}^{\text {eff }}\left(\mathrm{r}_{2}, \mathrm{u}_{4}\right)+I_{\text {int }}^{\text {eff }}\left(\mathrm{r}_{1}, \mathrm{r}_{5}\right)\right]$.

A procedure shall now be applied to solve the equation.

Then, let us consider, the Extrinsic Interoperability Score. Like for intrinsic assessment, let us define equations in an informal way. Potential (respectively Effective) extrinsic interoperability score of two OUs $O U_{a}$ and $O U_{b}$ equals to the sum of Potential (Effective) Extrinsic Interoperability Score of each potential (effective) couples ( $p a, p b)$ constituted by a partner belonging to of each OU. In a more formal way, Extrinsic Interoperability Score is defined as:

$$
\begin{aligned}
& I_{\text {ext }}^{x}\left(O U_{a}, O U_{b}\right)=\sum_{i=1}^{n a} I_{\text {ext }}^{x}\left(c_{i}\right) \\
& I_{\text {ext }}^{x}\left(O U_{a}, O U_{b}\right)=\sum_{i=1}^{n a} \sum_{j=1}^{n b} I_{\text {ext }}^{x}\left(p a_{i}, p b_{j}\right)
\end{aligned}
$$

With

$$
\begin{array}{ll}
- & x={ }^{\prime} \text { eff'or 'pot' } \\
\text { - } & n a=\operatorname{card}\left(\operatorname{Dec}\left(O U_{a}\right)\right) \\
\text { - } & n b=\operatorname{card}\left(\operatorname{Dec}\left(O U_{b}\right)\right) \\
\text { - } & p a_{i} \in \operatorname{Dec}\left(O U_{a}\right) \text { and } p b_{j} \in \operatorname{Dec}\left(O U_{b}\right) \\
\text { - } & c_{i} \in \operatorname{CE}^{x}\left(O U_{a}, O U_{b}\right)
\end{array}
$$

We illustrate the application of this formula on the same example as for intrinsic assessment and get :

$$
\begin{aligned}
& I_{\text {ext }}^{x}\left(O U_{a}, O U_{b}\right)=I_{\text {ext }}^{x}\left(\mathrm{r}_{1}, \mathrm{r}_{3}\right)+I_{\text {ext }}^{x}\left(\mathrm{r}_{1}, \mathrm{r}_{5}\right)+I_{\text {ext }}^{x}\left(\mathrm{r}_{1}, \mathrm{u}_{4}\right)+ \\
& I_{\text {ext }}^{x}\left(\mathrm{r}_{2}, \mathrm{r}_{3}\right)+I_{\text {ext }}^{x}\left(\mathrm{r}_{2}, \mathrm{u}_{4}\right)+I_{\text {ext }}^{x}\left(\mathrm{r}_{1}, \mathrm{r}_{5}\right) .
\end{aligned}
$$

Here again, we need to apply assessment procedure to know how to compute each term of the equation. Procedures require questionnaires and explanations about how to interpret them. We address these topics in next Section 


\section{QUESTIONNAIRES AND THEIR MATHEMATICAL INTERPRETATIONS}

We have seen that whatever the nature of the organisation (OU) that is assessed, it can finally be reduced to the assessment of the resources that are included within it. Therefore, many questionnaires are required to support assessment methods according to assessment type performed and the nature of resource. Every time a questionnaire is needed, we propose a typical one along with recommendations to improve interoperability and clear identification by question of interoperability barriers they aim to remove. The following sub-sections presents the two kinds of questionnaires we propose along with their mathematical interpretations. Let us notice that we do not present all questionnaires specific to every assessment types and kinds of resources here for space-saving reasons.

\subsection{Questionnaire for intrinsic assessment of atomic $O U$}

\section{Example of typical questionnaire}

To assess intrinsic interoperability, a set of questions is asked according the type (potential/effective) assessed. All questions shall be answered (i.e. a "NO" does not stop the assessment) and the sum of all "YES" gives the score. Figure 8 provides an example for the assessment of potential interoperability of a Non-Human Resource.

\section{Mathematical interpretation}

All questionnaires defined for the assessment of intrinsic interoperability have different questions but the same form and thus require the same method to interpret them. On Figure 5, we have seen that the first step when executing procedure for atomic OU, is to select formula to compute. For intrinsic assessment, the following formula is provided:

$$
\begin{aligned}
I_{i n t}^{x}\left(U O_{a}\right) & =\left\{I_{i n t}^{x}(\mathrm{r}) \mid \mathrm{r} \in R\right\} \\
& =\frac{\sum_{i=1}^{n q\left(Q_{k}\right)} \text { ans }\left(q_{i}\right)}{n q\left(Q_{k}\right)}
\end{aligned}
$$

With:

- The variable $x$ is used to indicate the type of interoperability that is assessed: intrinsic potential or effective.

- $\quad$ ans $\left(q_{i}\right)$ : interpretation of the question $q_{i}$ that equals 1 if the answer is "true" and 0 if not.

- $\quad n q\left(Q_{k}\right)$ : number of questions of the questionnaire $Q_{k}$

\section{Application example}

Let us exemplify the intrinsic assessment of a resource, on the basis of the questionnaire provided in Figure 8, and method for atomic OU assessment described in Figures 5 and 6.

Step A.2.1. We choose the questionnaire for Nonhuman resource potential intrinsic interoperability assessment.

- $\quad$ Step A.2.2. Figure 8 includes answers.
- $\quad$ Step A.2.3. The interpretation of answers provides the following values : ans $\left(q_{1}\right)=1$; ans $\left(q_{2}\right)=1$; ans $\left(q_{3}\right)=1 ;$ ans $\left(q_{4}\right)=0 ;$ ans $\left(q_{5}\right)=0$; ans $\left(q_{6}\right)=1 ;$ ans $\left(q_{7}\right)=0 ;$ ans $\left(q_{8}\right)=1$; ans $\left(q_{9}\right)=0$; ans $\left(q_{10}\right)=0$

- Step A.2.4. The application of the formula gives:

$$
\begin{aligned}
I_{\text {int }}^{\text {pot }}\left(O U_{a}\right) & =\frac{(1+1+1+0+0+1+0+1+0+0)}{10} \\
& =5 / 10
\end{aligned}
$$

Therefore, the intrinsic potential interoperability score of the resource "Software Test Bench Simulation Computer" at the moment of the assessment is 50\%. Topics addressed by questions 4,5,7,9,10 should be looked carefully by the deployment team to identify possible improvements.

\subsection{Questionnaire for extrinsic assessment}

\section{Example of typical questionnaire}

To assess extrinsic interoperability, a set of questions is proposed according the type (potential/effective) of assessment desired. The person in charge of the assessment starts with first question, gets an answer, and follows instructions provided. While he is invited to go to next question, the assessment goes on. However, when a "case End" is reached, the assessment is over and the result is provided by variable "S" (see Figure 9 for an example).

\section{Mathematical interpretation}

Like for intrinsic assessment, the variable " $x$ " indicates the type of interoperability that is assessed: extrinsic potential or effective. The formula for extrinsic interoperability assessment of two OUs according to questionnaire results is then:

$I_{\text {ext }}^{x}\left(O U_{a}, O U_{b}\right)=\left\{I_{\text {ext }}^{x}\left(r_{a}, r_{b}\right) \mid\left(r_{a}, r_{b}\right) \in R^{2}\right\}=\frac{u_{n q\left(Q_{k}\right)-1}}{n q\left(Q_{k}\right)}$

With the suite $\left(u_{n}\right)$ defined as:

$$
\left\{\begin{array}{c}
\mathrm{u}_{0}=1 \\
\mathrm{u}_{\mathrm{n}+1}=\mathrm{u}_{\mathrm{n}}+\prod_{\mathrm{i}=1}^{\mathrm{n}+1} \text { ans }\left(q_{i}\right)
\end{array}\right.
$$

\section{Application example}

As before, let us apply the method on the example provided in Figure 9.

- Step A.2.1. We choose the questionnaire for Nonhuman resource effective extrinsic interoperability assessment.

- $\quad$ Step A.2.2. Figure 9 includes answers

- Step A.2.3. The interpretation of answers provides the following values: ans $\left(q_{1}\right)=1$; ans $\left(q_{2}\right)=1$; ans $\left(q_{3}\right)=1 ;$ ans $\left(q_{4}\right)=1 ;$ ans $\left(q_{5}\right)=1$; ans $\left(q_{6}\right)=0$; ans $\left(q_{7}\right)=0$;

- Step A.2.4. The application of the formula gives:

$$
\begin{aligned}
I_{\text {ext }}^{x}\left(O U_{a}, O U_{b}\right)= & (1+1+1.1+1.1 .1+1.1 .1 .1+1.1 .1 .1 .1 \\
& +1.1 .1 .1 .1 .0) / 7 \\
= & 5 / 7
\end{aligned}
$$


Therefore, the extrinsic effective interoperability score of the two resources "Monitor simulating helmet symbology" and "Software Test Bench Simulation Computer" at the moment of the assessment is around $71 \%$. Topics addressed in question 6 should be examined by the deployment team for improvements.

Consequently this Section presents how to use and interpret questionnaires. One strength of this kind of solution is that it is very pragmatic so it does not put managers off and requires very few training effort. Moreover, it is a very open-ended solution since the company can change the number or the labels of questions for example.

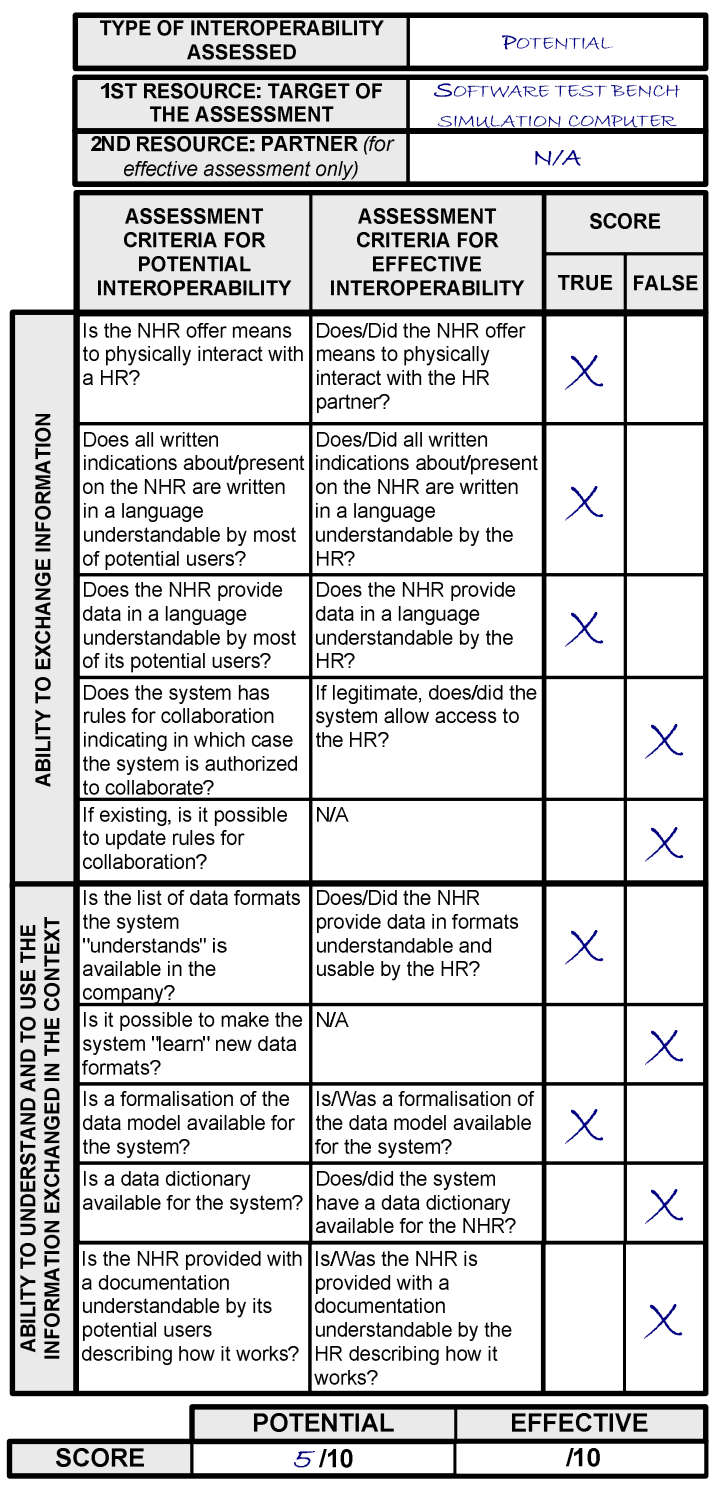

Fig. 8. Example of questionnaire for Non-human resource potential intrinsic interoperability assessment

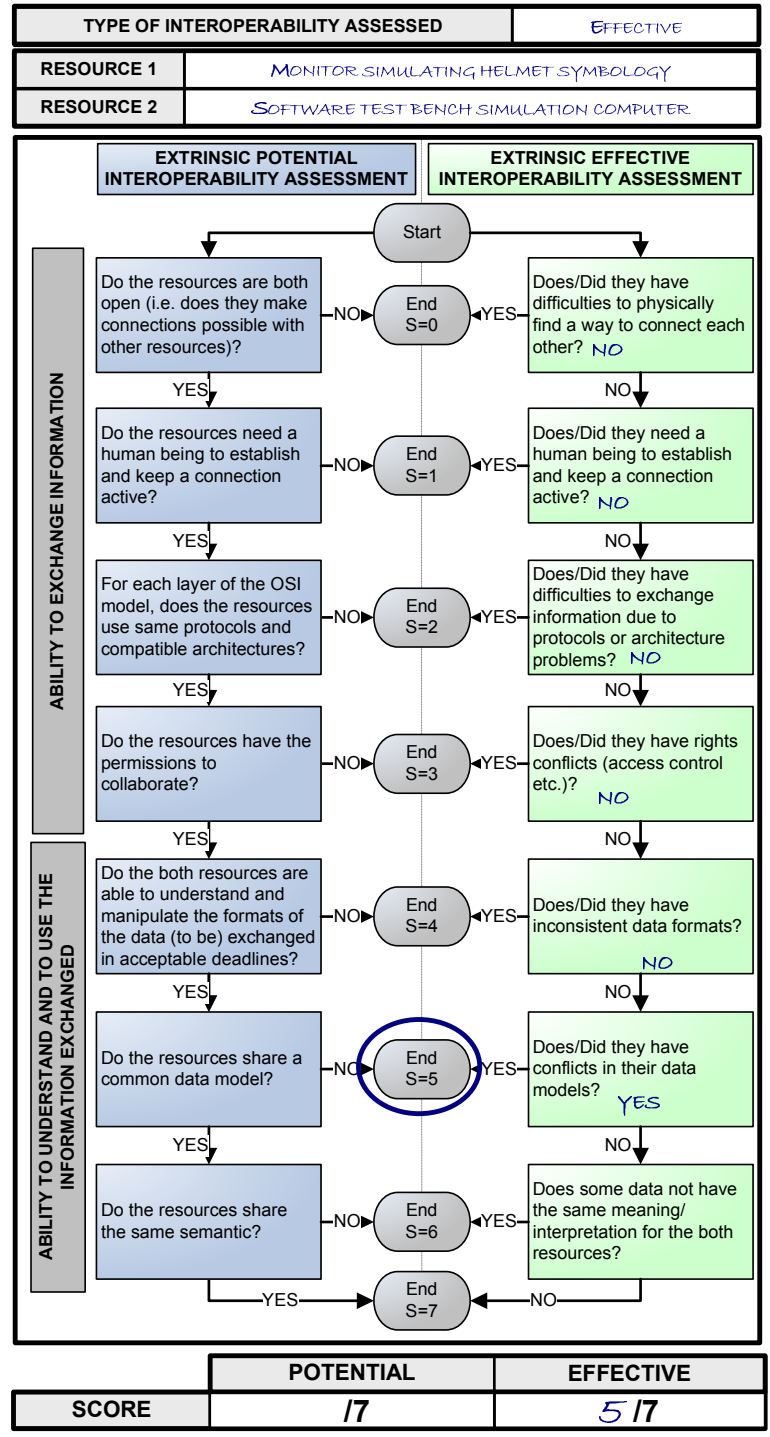

Fig. 9. Example of questionnaire for Non-human resources effective extrinsic interoperability assessment

\section{CONCLUSION}

By hypothesis in the presented research work, interoperability is considered as a condition of success for process deployment in companies that should be assessed all along deployment stages. To that end, this paper presents the principles of a methodology to assess interoperability of resources involved or that could be involved in processes. It includes a meta-model, an assessment process, a set of procedures along with their mathematical formalisation, and a set of questionnaires to collect information required for the assessment along with their interpretation method. It can be applied on single or couples of resources and is applicable not only once collaboration has started but also before a collaboration to anticipate future difficulties.

This assessment method appears useful to: 
- be used as a "camera" that takes an initial picture of the entity to prepare deployment efficiency assessment,

- $\quad$ highlight interoperability problems in order to find clues about where new processes should provide improvements, improve interoperability abilities of entities before the deployment in order to maximize its chances of success,

- be used as a guide for resource allocation. Indeed, it enables making a choice between two entities and checking if resources considered for the new processes are able to work together.

- be used a verification tool that enables not only checking that resources that are planned to work together do not experiment interoperability problems but also that the deployment has improved the global performance of the organisation concerned.

From a semantic point of view, this method is based on a meta-model enabling a shared understanding between all people concerned with the interoperability assessment. Its strength is its design made by and for industrials, and thus thought to be easily and directly applicable in industry with the possibility to get easily automated. This method is currently tested within a helicopter manufacturer for the deployment of Systems Engineering processes, and the software application enabling its automation is under development.

\section{REFERENCES}

[1] C. Cornu, V. Chapurlat, B. Chiavassa, and F. Irigoin, "Mixing Systems Engineering and Enterprise Modelling principles to formalize a SE processes deployment approach in industry," in CSD\&M, Paris, France, 7-9 December 2011, Springer Berlin Heidelberg, 2011, pp. 201-210.

[2] ISO/IEC, "ISO/IEC 15288:2008 - Systems engineering - System life cycle processes," 2008.

[3] ISO, "ISO/DIS 11354-1 - Advanced automation technologies and their applications - Part 1: Framework for enterprise interoperability," 2010.

[4] INTEROP-NoE Project, "Deliverable DI.2 Enterprise Interoperability-Framework and knowledge corpus-Advanced report," 2006.

[5] N. Daclin, "Contribution au développement d'une méthodologie pour l'interopérabilité des entreprises," Université Bordeaux 1, 2007.

[6] G. E. Lavean, "Interoperability in Defense Communications," IEEE transactions on communications, vol. Com-28, no. 9, 1980.

[7] C4ISR, "Levels of Information Systems Interoperability (LISI)," 1998.

[8] T. Clark and R. Jones, "Organisational Interoperability Maturity Model for C2," in ICCRTS 1999, United States Naval War College, Newport, 1999.

[9] IEC, "IEC TR 62390:2005 - Common automation device - Profile guideline," 2005.

[10] A. Tolk and J. A. Muguira, "The Levels of Conceptual Interoperability Model," in 2003 Fall Simulation Interoperability Workshop, Orlando, Florida, 2003.
[11] P. Fraser, C. Farrukh, and M. Gregory, "Managing product development collaborations-a process maturity approach," Institution of Mechanical Engineers, Part B: Journal of Engineering Manufacture, vol. 217, no. 11, 2003.

[12] ATHENA Project, "Deliverable D.A1.4.1 Framework for the Establishment and Management Methodology," 2005.

[13] G. Kingston, S. Fewell, and W. Richer, "An organisational interoperability agility model," in ICCRTS 2005, 2005.

[14] NEHTA, "Interoperability Maturity Model - Version 1.0," 2007.

[15] I. Santos, S. Schuster, M. Vergara, and J. Alonso, "Assessing the Readiness for Enterprise Collaboration and Enterprise Interoperability," in 14th International Conference on Concurrent Enterprising, Lisbon, Portugal, 23 - 25 June 2008, 2008.

[16] W. Guédria, D. Chen, and Y. Naudet, "A Maturity Model for Enterprise Interoperability," in OTM 2009 Workshops, 2009, pp. 216-225.

[17] I. M. D. Soria, J. Alonso, L. Orue-Echevarria, and M. Vergara, "Developing an Enterprise Collaboration Maturity Model: Research Challenges and Future Directions," in 15th International Conference on Concurrent Enterprising, Leiden, Netherlands, 22 24 June 2009, 2009.

[18] M. J. Leite, "Interoperability Assessment," in 66th Military Operations Research Society Symposium. Monterey, CA, June 23-25, 1998, 1998.

[19] J. Hamilton, J. Rosen, and P. Summers, “An Interoperability Road Map for C4ISR Legacy Systems," 2002.

[20] K. Stewart, H. Clarke, P. Goillau, N. Verrall, and M. Widdowson, "Non-Technical Interoperability in Multinational Forces," in ICCRTS 2004, 2004.

[21] T. Ford, J. Colombi, S. Graham, and D. Jacques, "The Interoperability Score," in CSER 2007, March 14-16, Hoboken, NJ , USA, 2007.

[22] N. Daclin, D. Chen, and B. Vallespir, "Methodology for Enterprise Interoperability," in 17th IFAC World Congress - Seoul, Korea, July 6-11, 2008, 2008.

[23] E. Yahia, M. Lezoche, A. Aubry, and H. Panetto, "Semantics enactment for interoperability assessment in Enterprise Information Systems," Annual Reviews in Control, vol. 36, no. 1, pp. 101-117, Apr. 2012.

[24] LeMoigne, La théorie du système général: théorie de la modélisation. 1994.

[25] J.-A. Estefan, "Survey of Model-Based Systems Engineering (MBSE) Methodologies," 2008.

[26] J. J. Lesage, “Conception De La Commande Des Systemes De Production $\square$ : Contribution A La Structuration, Application A La Conception De La Commande d'un Atelier Flexible," Ecole Centrale Paris/LURPA/ENS Cachan, 1989.

[27] OMG, Business Process Model and Notation (BPMN) - Version 2.0. 2011. 